\title{
The Evaluation of the Malignant Characteristics of Conjunctival Lesions Based on the Dermatoscopic Algorithm
}

\author{
MAGDALENA DĘBICKA-KUMELA ${ }^{1,2}$, BOZENA ROMANOWSKA-DIXON $^{1,2}$, \\ IZABELLA KARSKA-BASTA ${ }^{1,2}$, JOANNA KOWAL ${ }^{1,2}$ and ANNA MARKIEWICZ ${ }^{1,2}$ \\ ${ }^{1}$ Jagiellonian University Medical College, Faculty of Medicine, \\ Department of Ophthalmology and Ocular Oncology, Krakow, Poland; \\ ${ }^{2}$ Department of Ophthalmology and Ocular Oncology, University Hospital, Krakow, Poland
}

\begin{abstract}
Background/Aim: This study analysed the prevalence of the characteristics evaluated in dermatoscopy for melanocytic infiltrations of the conjunctiva with various degrees of malignancy. Patients and Methods: A total of 160 conjunctival pigmented lesions were studied. Each lesion was scored using dermatoscopic patterns and the characteristics of malignancy described by Kittler. Also, the Authors' own clues were added to the evaluation. Results: In melanomas, the following characteristics were identified: asymmetry of the pattern and colour, larger average number of colours, the presence of grey colour, structureless area, polymorphic vessels and feeder vessels. A pattern of black dots and a black colour was typical of malignant lesions and pre-cancerous (premalignant) lesions - primary acquired melanosis (PAM) with atypia. Cysts were observed only in the group of naevi. Conclusion: The patterns evaluated with dermatoscopy are present in pigmented lesions of the conjunctiva. There are, however, some characteristics which allow differentiation between melanoma and pigmented naevus and melanosis and also between PAM.
\end{abstract}

There are several lesions that arise from the melanocytes of the conjunctiva. The most common are naevi, primary acquired melanosis (PAM) and malignant melanoma (MM). The predominant conjunctival pigmented tumour is naevus $(1,2)$. Naevus accounts for $28 \%$ of all conjunctival tumours and 52\% of melanocytic lesions (3). It is a benign lesion, with a less than

This article is freely accessible online.

Correspondence to: Anna Markiewicz, MD, Ph.D., Jagiellonian University Medical College, Faculty of Medicine, Department of Ophthalmology and Ocular Oncology, Kopernika 38, 31-501 Krakow, Poland. Tel: +48 124247540, Fax: +48 124247563, e-mail: anna.markiewicz@uj.edu.pl or annamarkiewicz@interia.pl

Key Words: Conjunctiva, melanoma, naevus, PAM, dermatoscopy.
$1 \%(3,4)$ tendency to malignant transformation. It is usually a unilateral, slightly elevated, variably pigmented lesion, with clear cysts, and feeder vessels, and is predominantly located in the bulbar conjunctiva (3). All naevi require serial observation using photographic documentation. Any changes in size, shape or colour are suspicious of malignant transformation and should be treated like melanoma. Some patients demand excision for cosmetic reasons $(4,5)$.

PAM accounts for $11 \%$ of all conjunctival tumours and $21 \%$ of conjunctival pigmented lesions $(2,6,7)$. It can be divided into melanosis with atypia and without atypia, depending on the nuclear features and growth pattern of melanocytes in the histopathological examination. The presence of atypia is associated with a very high risk (13$50 \%$ ) of malignant transformation, while absence of atypia carries no risk for melanoma development (4-6). PAM with atypia is considered to be a form of melanoma in situ, similar to lentigo maligna of the skin $(6,8)$. PAM occurs as a flat, unilateral, brown, patchy or diffuse lesion usually in middleaged Caucasian individuals (9). It is thought that it is impossible to distinguish clinically PAM without atypia from PAM with atypia (4). PAM must be differentiated from racial melanosis, which is usually bilateral and symmetrical (6). The procedure proposed by Shields and co-workers in patients with PAM involves observation or surgical treatment in combination with cryotherapy and/or topical chemotherapy depending on the size of the lesion. In cases of very large tumours, map biopsies with freeze thaw cryotherapy to all remaining areas of pigment is recommended $(4,6)$.

Conjunctival melanoma (CMM) is a rare, but potentially lethal tumour. It can arise de novo (37\%) or from precursors. Most of the tumours originate from PAM with atypia (53\%$75 \%$ ), and only about $4 \%$ from naevi (4-6, 9-13). Patients with melanoma from precursors demonstrate better survival compared with those arising de novo (12). CMM causes local and systemic metastases in $32 \%$ of cases within a 15 -year follow-up period $(5,12,14)$. Metastases to lymph nodes, the liver, brain, lungs and skin are the most common sites $(5,8$, 
13). The mortality rate is between $13-40 \%$ over ten years $(8$, $9,11,15)$. Local tumour recurrence has been reported in 50$70 \%$ of patients $(4,5,12,16)$. CMM mostly appears in the perilimbal bulbar conjunctiva, and presents usually as a pigmented (infrequently non pigmented), elevated, immobile, vascularised mass of short duration $(4,8,16)$. Total surgical (with wide margin) excision using the "no touch" technique with adjuvant cryotherapy to the margins and alcohol corneal epitheliectomy is usually recommended. The treatment can be supplemented with brachytherapy or topical chemotherapy with mitomycin-C or immunotherapy with interferon-alpha2b. Advanced CMM may require orbital exenteration and/or irradiation therapy $(4,5,8,16-18)$.

The early diagnosis of melanoma is extremely important in reducing mortality. Accurate diagnosis of melanocytic conjunctival lesions is essential for designing treatment. We are searching for techniques which can increase accuracy in the diagnosis of conjunctival pigmented lesions. The algorithmic method based on pattern analysis by Harald Kittler (chaos and clues) is used by dermatologists to differentiate melanoma from other melanocytic skin lesions $(19,20)$. It is based on certain dermatoscopic structures that create repetitive patterns characteristic of a particular group of pigmented lesions. The objective of our work was to compare and estimate the prevalence of the characteristic features evaluated in dermatoscopy for conjunctival melanocytic tumours such as naevus, PAM with and without atypia and melanoma. All of these are taken into consideration in the algorithms used in dermatoscopy, for distinguishing and differentiating between melanocytic lesions of the skin.

\section{Patients and Methods}

Materials. A total of 160 conjunctival pigmented lesions (40 cases of histopathologically proven naevi, 40 PAM with atypia, 40 PAM without atypia and 40 with melanoma) on 158 patients (median age 50.5 years; age range $=5-87$ years) were recruited. There were 83 tumours in men and 77 in women. Patients were diagnosed and treated in our Department of Ophthalmology between 2015 and 2018. The detailed characteristics of the examined group, depending on individual histopathological categories, are presented in Table I.

Patients and settings. The study was performed on clinically pigmented melanocytic conjunctival lesions, qualified for surgical excision due to suspected malignancy or cosmetic reasons. Then, after histopathological assessment, 4 groups of 40 consecutive nonselected cases of naevi, PAM without atypia, PAM with atypia and melanoma were distinguished; in these groups the ophthalmological assessment was performed earlier according to the protocol presented below. Eyelid margin tumours were excluded.

Examined lesion diagnosis. For the purposes of the study, a protocol for the ophthalmological examination of the conjunctival lesions qualified for excision was prepared. The protocol provided for the re-assessment was created by 3 independent ophthalmologists with extensive experience in ocular oncology, who, in the assessment
Table I. Demographic data depending on histopathological diagnosis.

\begin{tabular}{lcccc}
\hline $\begin{array}{c}\text { Histopathological } \\
\text { diagnosis }\end{array}$ & Age & Male & Female & Children \\
\hline $\begin{array}{c}\text { Naevus } \\
(\mathrm{n}=40)\end{array}$ & $39.3 \pm 19.4$ & $24(60.0)$ & $16(40.0)$ & $6(15.0)$ \\
$\begin{array}{c}\text { PAM without } \\
\text { atypia (n=40) }\end{array}$ & $40.3 \pm 21.7$ & $25(62.5)$ & $15(37.5)$ & $6(15.0)$ \\
$\begin{array}{c}\text { PAM with atypia } \\
(\mathrm{n}=40)\end{array}$ & $59.9 \pm 17.1$ & $16(40.0)$ & $24(60.0)$ & $0(0.0)$ \\
$\begin{array}{c}\text { Melanoma } \\
(\mathrm{n}=40)\end{array}$ & $62.7 \pm 17.7$ & $18(45.0)$ & $22(55.0)$ & $0(0.0)$ \\
\hline
\end{tabular}

report, took into consideration Harald Kittler's algorithms used in dermatoscopy (19). The lesions were described on the basis of the examination of the anterior section of the eye (biomicroscopic examination), without a preliminary diagnosis. Then, a coloured drawing of the tumour was made with a description and also a coloured photograph taken with an 8-, 12- and 20-fold magnification. For the study, a slit lamp with SL-imaging system, with fully integrated digital camera SL Cam 5.0 (The Carl Zeiss Meditec Group, Jena, Germany) was used. Thanks to the application of a diffusor filter and 8-, 12- and 20-fold magnification, the examination conditions were similar to contactless dermatoscopy. A histopathologic examination was performed in all cases, by a pathologist experienced in ocular oncology.

Clinical data. The following data were collected for each tumour: the demographic information of the patient, the elevation of the lesion, the presence of colour: brown (differentiation into light and dark brown), black, white, pink and grey. The number of colours observed with a slit lamp was also counted. The colour of the surrounding conjunctiva was regarded as a point of reference and only the colours which differed from it were evaluated. Each lesion was scored using dermatoscopic patterns described by Kittler and colleagues: dots, globules, pseudopods, circles, lines and structureless zones (if none of the basic elements were present) (19). In the case of more than one pattern and colour, their symmetry was assessed. "Chaos" was defined as a lack of symmetry of the structure (pattern) or colour. The presence of clues to malignancy such as: polymorphous vessels, an eccentric structureless zone (any colour except the conjunctiva), a grey and structureless area and segmental pseudopods were also examined. In addition, the authors' own clues, such as: the presence of black dots within the entire volume of the lesion (not only placed peripherally), feeder vessels and cysts, were added to the evaluation. In addition to these criteria, a vascular pattern was also examined: dots, globules, lines (straight, loop-shaped, curved, serpentine-like, coil-like, glomus-like), the presence of short and long vessels. The presence of more than one vascular pattern was described as polymorphous vessels. Vessels were calculated only when they had a different pattern from the surrounding conjunctiva.

Statistical analysis. Continuous data were presented as a mean value and standard deviation (SD). Categorical data were presented as percentages. Normal distribution was verified by the KolmogorovSmirnov test. Continuous data from two groups were compared by 
Table II. The comparison of dermatoscopy results between the naevi and conjunctival melanoma groups.

\begin{tabular}{|c|c|c|c|}
\hline & $\begin{array}{l}\text { Naevus } \\
(n=40)\end{array}$ & $\begin{array}{l}\text { Melanoma } \\
\quad(\mathrm{n}=40)\end{array}$ & $p$-Value \\
\hline Elevated lesion & $19(47.5)$ & $15(37.5)$ & 0.366 \\
\hline Partly elevated lesion & $3(7.5)$ & $14(35.0)$ & 0.003 \\
\hline \multicolumn{4}{|l|}{ Pattern } \\
\hline Number of patterns & & & 0.152 \\
\hline 1 & $10(25.0)$ & $5(12.5)$ & \\
\hline$\geq 2$ & $30(75.0)$ & $35(87.5)$ & \\
\hline Pattern asymmetry (chaos) & $4(10.0)$ & $30(75.0)$ & $<0.001$ \\
\hline Lines & $9(22.5)$ & $15(37.5)$ & 0.143 \\
\hline Dots & $30(75.0)$ & $31(77.5)$ & 0.793 \\
\hline Globules & $3(7.5)$ & $5(12.5)$ & 0.712 \\
\hline Circles & $6(15.0)$ & $1(2.5)$ & 0.108 \\
\hline Pseudopods & $1(2.5)$ & $7(17.5)$ & 0.057 \\
\hline Structureless & $26(65.0)$ & $39(97.5)$ & $<0.001$ \\
\hline \multicolumn{4}{|l|}{ Colour } \\
\hline Number of colours, average & $1.7 \pm 0.6$ & $2.9 \pm 1.0$ & $<0.001$ \\
\hline \multicolumn{4}{|l|}{ Number of colours: } \\
\hline 1 & $16(40.0)$ & $2(5.0)$ & $<0.001$ \\
\hline 2 & $21(52.5)$ & $11(27.5)$ & \\
\hline 3 & $3(7.5)$ & $17(42.5)$ & \\
\hline 4 & $0(0.0)$ & $9(22.5)$ & \\
\hline 5 & $0(0.0)$ & $0(0.0)$ & \\
\hline 6 & $0(0.0)$ & $1(2.5)$ & \\
\hline More than 2 colours & $3(7.5)$ & $27(67.5)$ & $<0.001$ \\
\hline Colour asymmetry (chaos) & $4(10.0)$ & $31(77.5)$ & $<0.001$ \\
\hline Light brown & $30(75.0)$ & $25(62.5)$ & 0.228 \\
\hline Dark brown & $17(42.5)$ & $27(67.5)$ & 0.025 \\
\hline Black & $4(10.0)$ & $23(57.5)$ & $<0.001$ \\
\hline White & $0(0.0)$ & $6(15.0)$ & 0.026 \\
\hline Gray & $6(15.0)$ & $19(47.5)$ & 0.002 \\
\hline Rose & $10(25.0)$ & $16(40.0)$ & 0.152 \\
\hline \multicolumn{4}{|l|}{ Blood vessels } \\
\hline \multicolumn{4}{|l|}{$\begin{array}{l}\text { Symmetry of the vascular } \\
\text { pattern: }\end{array}$} \\
\hline Polymorphous vessels & $6(15.0)$ & $20(50.0)$ & 0.001 \\
\hline Monomorphous vessels & $20(50.0)$ & $6(15.0)$ & \\
\hline No vessels & $14(35.0)$ & $14(35.0)$ & \\
\hline Vessels dots & $6(15.0)$ & $16(40.0)$ & 0.012 \\
\hline Vessels globules & $2(5.0)$ & $4(10.0)$ & 0.675 \\
\hline Vessels lines: & $24(60.0)$ & $25(62.5)$ & 0.818 \\
\hline Straight & $6(15.0)$ & $20(50.0)$ & 0.001 \\
\hline Loop-shaped & $1(2.5)$ & $5(12.5)$ & 0.201 \\
\hline Curved & $13(32.5)$ & $9(22.5)$ & 0.317 \\
\hline Serpentine-like & $11(27.5)$ & $13(32.5)$ & 0.626 \\
\hline Coil-like & $0(0.0)$ & $6(15.0)$ & 0.026 \\
\hline Glomus-like & $0(0.0)$ & $2(5.0)$ & 0.494 \\
\hline Short vessels & $14(35.0)$ & $24(60.0)$ & 0.025 \\
\hline Long vessels & $18(45.0)$ & $18(45.0)$ & 1.000 \\
\hline \multicolumn{4}{|l|}{ Location of the vessels } \\
\hline Random & $11(27.5)$ & $20(50.0)$ & 0.039 \\
\hline Linear & $0(0.0)$ & $1(2.5)$ & 1.000 \\
\hline Radial & $2(5.0)$ & $0(0.0)$ & 0.494 \\
\hline In groups & $1(2.5)$ & $1(2.5)$ & 1.000 \\
\hline Central & $0(0.0)$ & $0(0.0)$ & - \\
\hline Reticular & $0(0.0)$ & $1(2.5)$ & 1.000 \\
\hline Branched & $20(50.0)$ & $23(57.5)$ & 0.501 \\
\hline \multicolumn{4}{|l|}{ Clues to malignancy } \\
\hline Eccentric structureless zone & $1(2.5)$ & $11(27.5)$ & 0.002 \\
\hline Gray structureless area & $4(10.0)$ & $20(50.0)$ & $<0.001$ \\
\hline Black dots & $3(7.5)$ & $22(55.0)$ & $<0.001$ \\
\hline Segmental pseudopods & $1(2.5)$ & $8(20.0)$ & 0.029 \\
\hline Peripheral feeder vessel & $4(10.0)$ & $16(40.0)$ & 0.002 \\
\hline Cysts & $14(35.0)$ & $0(0.0)$ & $<0.001$ \\
\hline
\end{tabular}

Significant $p$-Values are shown in bold.
Student's $t$-test or by the Mann-Whitney $U$-test, depending on the distribution. More than two groups were compared by univariate analysis of variance (ANOVA) followed by the Least Significant Difference (LSD) test or by the Kruskall-Wallis test depending on the distribution. Categorical data were compared by the Chi-square test and Fisher's exact test. Data were analysed using SPSS software v.21 (IBM, Armonk, NY, USA).

Authors declare that this investigation was carried out following the rules of the Declaration of Helsinki of 1975 (revised in 2013).

\section{Results}

On the basis of the ophthalmological examination, carried out according to the accepted protocol, it was found that the malignant tumours and premalignant lesions (MMC and PAM with atypia) occurred more frequently in older subjects (around 60 years of age on average), than benign lesions (naevi and PAM without atypia), which were observed more frequently in younger patients (around 40 years of age) $(p<0.001)$. In children, only benign tumours were observed (PAM without atypia and naevi). The dots pattern was the most frequent one in all the examined groups.

A white colour was observed only in the case of CMM, and cysts - in the case of pigmented naevi. No blue colour was observed in any of the examined infiltrations.

The comparison of CMM with a naevus and PAM with atypia. Many significant differences were observed in the comparative analyses of the examination results of the patient groups with conjunctival melanoma, benign pigmented naevus (Table II), melanoma and premalignant lesion i.e. PAM with atypia (Table III).

Type of infiltration. PAM with atypia most frequently comprises flat lesions, as opposed to melanomas $(p<0.001)$ and naevi, where elevated lesions were more often found. Melanomas, significantly more frequently than naevi, were found to be partly elevated tumours $(p=0.003)$ (Figure 1).

Pattern analysis. The studied groups of patients (CMM, PAM with atypia and naevi) were similar to each other with regards to the number of patterns. They differed, however, with respect to the presence of the following properties: amorphous pattern $(p<0.001)$, asymmetry of the pattern and colour $(p<0.001)$, higher average number of colours $(p<0.001)$ and more than 2 colours per lesion $(p<0.001)$, which were observed significantly more frequently in the case of CMM than in the case of naevi and PAM with atypia.

In CMM, in comparison with naevus, the clues to malignancy with the polymorphic vessel type were described much more frequently $(p=0.001)$; the same situation concerned black dots $(p<0.001)$, amorphous grey areas $(p<0.001)$, peripheral amorphous areas $(p=0.002)$ and peripheral feeder vessels $(p=0.002)$. 
Table III. The comparison of dermatoscopy results between PAM with atypia and conjunctival melanoma groups.

\begin{tabular}{|c|c|c|c|}
\hline & $\begin{array}{l}\text { PAM with } \\
\text { atypia }(n=40)\end{array}$ & $\begin{array}{l}\text { Melanoma } \\
(\mathrm{n}=40)\end{array}$ & $p$-Value \\
\hline Elevated lesion & $1(2.5)$ & $15(37.5)$ & $<0.001$ \\
\hline Partly elevated lesion & $0(0.0)$ & $14(35.0)$ & $<0.001$ \\
\hline \multicolumn{4}{|l|}{ Pattern } \\
\hline Number of patterns: & & & 0.363 \\
\hline 1 & $8(20.0)$ & $5(12.5)$ & \\
\hline$\geq 2$ & $32(80.0)$ & $35(87.5)$ & \\
\hline Pattern asymmetry (chaos) & $10(25.0)$ & $30(75.0)$ & $<0.001$ \\
\hline Lines & $18(45.0)$ & $15(37.5)$ & 0.496 \\
\hline Dots & $37(92.5)$ & $31(77.5)$ & 0.060 \\
\hline Globules & $2(5.0)$ & $5(12.5)$ & 0.432 \\
\hline Circles & $0(0.0)$ & $1(2.5)$ & 1.000 \\
\hline Pseudopods & $0(0.0)$ & $7(17.5)$ & 0.012 \\
\hline Structureless & $22(55.0)$ & $39(97.5)$ & $<0.001$ \\
\hline \multicolumn{4}{|l|}{ Colour } \\
\hline Number of colours, average & $2.1 \pm 0.8$ & $2.9 \pm 1.0$ & $<0.001$ \\
\hline \multicolumn{4}{|l|}{ Number of colours: } \\
\hline 1 & $9(22.5)$ & $2(5.0)$ & 0.004 \\
\hline 2 & $19(47.5)$ & $11(27.5)$ & \\
\hline 3 & $11(27.5)$ & $17(42.5)$ & \\
\hline 4 & $1(2.5)$ & $9(22.5)$ & \\
\hline 5 & $0(0.0)$ & $0(0.0)$ & \\
\hline 6 & $0(0.0)$ & $1(2.5)$ & \\
\hline More than 2 colours & $12(30.0)$ & $27(67.5)$ & 0.001 \\
\hline Colour asymmetry (chaos) & $10(25.0)$ & $31(77.5)$ & $<0.001$ \\
\hline Light brown & $21(52.5)$ & $25(62.5)$ & 0.366 \\
\hline Dark brown & $33(82.5)$ & $27(67.5)$ & 0.121 \\
\hline Black & $24(60.0)$ & $23(57.5)$ & 0.820 \\
\hline White & $0(0.0)$ & $6(15.0)$ & 0.026 \\
\hline Grey & $5(12.5)$ & $19(47.5)$ & 0.001 \\
\hline Pink & $1(2.5)$ & $16(40.0)$ & $<0.001$ \\
\hline \multicolumn{4}{|l|}{ Blood vessels } \\
\hline \multicolumn{4}{|l|}{$\begin{array}{l}\text { Symmetry of the vascular } \\
\text { pattern: }\end{array}$} \\
\hline Polymorphous vessels & $1(2.5)$ & $20(50.0)$ & $<0.001$ \\
\hline Monomorphous vessels & $1(2.5)$ & $6(15.0)$ & \\
\hline No vessels & $38(95.0)$ & $14(35.0)$ & \\
\hline Vessels dots & $0(0.0)$ & $16(40.0)$ & $<0.001$ \\
\hline Vessels globules & $0(0.0)$ & $4(10.0)$ & 0.116 \\
\hline Vessels lines & $2(5.0)$ & $25(62.5)$ & $<0.001$ \\
\hline Short vessels & $1(2.5)$ & $24(60.0)$ & $<0.001$ \\
\hline Long vessels & $1(2.5)$ & $18(45.0)$ & $<0.001$ \\
\hline \multicolumn{4}{|l|}{ Clues to malignancy } \\
\hline Eccentric structureless zone & $3(7.5)$ & $11(27.5)$ & 0.019 \\
\hline Gray structureless area & $5(12.5)$ & $20(50.0)$ & $<0.001$ \\
\hline Black dots & $25(62.5)$ & $22(55.0)$ & 0.496 \\
\hline Segmental pseudopods & $0(0.0)$ & $8(20.0)$ & 0.005 \\
\hline Peripheral feeder vessel & $0(0.0)$ & $16(40.0)$ & $<0.001$ \\
\hline Cysts & $0(0.0)$ & $0(0.0)$ & - \\
\hline
\end{tabular}

Significant $p$-Values are shown in bold.

In the case of CMM, vascular polymorphism was observed with significantly higher frequency than in PAM; and vascular polymorphism $(p<0.001)$, peripheral feeder vessels $(p<0.001)$, grey structureless areas $(p<0.001)$ and segmental pseudopods ( $p=0.005)$ were also found. The clue to malignancy of the black dots type was observed with a similar frequency in PAM with atypia and in melanoma (Figure 2).

Colour analysis. Melanomas contained a black colour $(p<0.001)$ or grey colour $(p=0.002)$ significantly more frequently than naevi, whilst in comparison with PAM with atypia - a pink colour $(p<0.001)$ or grey colour was observed $(p=0.001)$. A black colour was observed with similar frequency in the groups of premalignant and malignant lesions. A white colour, in turn, was seen only in CMM, yet this characteristic was not statistically significant.

The presence of cysts. Cysts were typical of pigmented naevi $(p<0.001)$ and in none of the cases melanoma or PAM was diagnosed (Figure 3).

A comparison between PAM without atypia and PAM with atypia. The comparison of the results of the ophthalmological assessment on the basis of the objectives of the dermoscopic analysis in the groups of PAM without atypia and with atypia are presented in Table IV. In both groups, flat infiltrations without vascularisation were predominant. The groups were also similar to each other with regards to the number of the patterns - most frequently the simultaneous presence of two types of patterns was observed: dots and lines. In the case of PAM with atypia, the presence of amorphous pattern was more frequent $(p<0.001)$, as well as asymmetry of pattern and colour $(p=0.001)$ and the presence of a black colour $(p<0.001)$ and black dots $(p<0.001)$. In the PAM without atypia group, the chaos pattern or colour were found in none of the cases. PAM without atypia was most frequently a single colour lesion (a light brown colour prevailed), whilst in PAM with atypia a double-colour or three-colour lesion was more often observed in which the prevailing colours were light and dark brown or black $(p<0.001)$. PAM with atypia also frequently contained a grey lesion, yet this was not statistically significant.

\section{Discussion}

Differential diagnostics of benign and malignant pigmented lesions of the conjunctiva in a slit lamp may pose a diagnostic problem, especially for doctors who do not deal with ophthalmological oncology on an everyday basis. The lack of widely available, simply to learn diagnostic algorithms, generates the risk of a delayed diagnosis of melanoma and may expose patients with benign lesions to unnecessary excisional biopsies. In dermatology, the algorithm developed by Kittler, which facilitates differentiation between malignant and benign lesions, has been used for many years (19). For this reason, we decided 


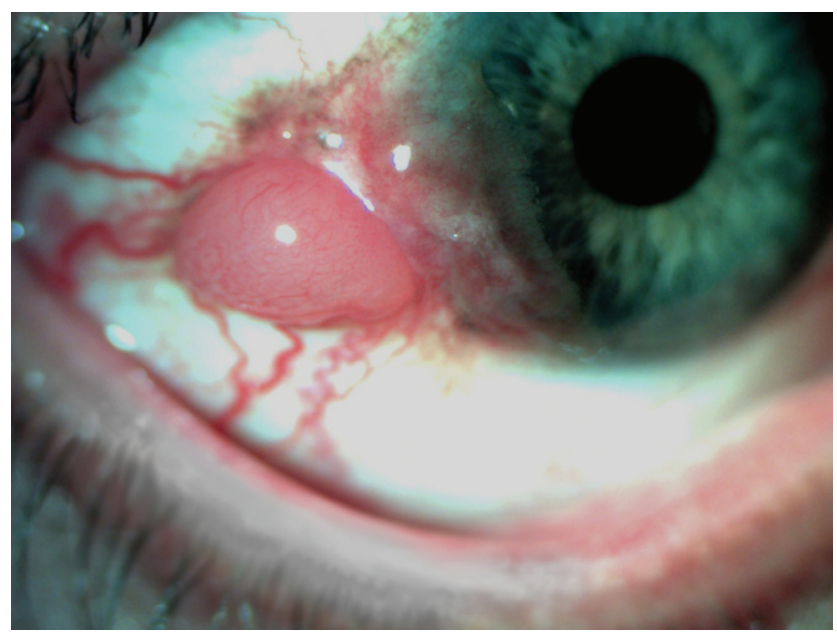

Figure 1. Conjunctival melanoma - some part of the lesion is flat, whilst some part of it nodular.

to analyse 4 groups of histologically different melanocytic lesions of the conjunctiva with respect to the properties evaluated in dermatoscopy.

There is a number of reports describing the results of the dermatoscopic assessment regarding the infiltration on mucosal membranes and a few case reports presenting the dermatoscopic picture of the conjunctival melanoma. Cinotti et al. have described the dermatoscopy results of 127 conjunctival tumours, yet among them there were also nonmelanocytic lesions and not all the elements used in the pattern analysis were described (21).

In our study, malignant and premalignant tumours (MMC and PAM with atypia) were more frequently found among patients with a mean age of 60 years, than benign lesions (naevi and PAM without atypia), which occurred on average around the age of 40 . This is compliant with the results of previous studies on pigmented tumours of other mucous membranes $(6,7,14,21-26)$.

In the evaluation of the tendency to form tumours, we observed that PAM, in the majority of the cases studied, was a flat pigmented lesion, whilst melanomas and naevi were elevated in a similar rate. Shields et al. have also observed that melanomas showed significant features of increased thickness compared to other pigmented lesions of the conjunctiva (24). However, the comparison of melanoma with pigmented naevus of the conjunctiva, showed that melanomas are most often only partly elevated (part of the lesion is flat and part is nodular), which is most probably related to their likely formation on the foundation of $\operatorname{PAM}(5,10,11)$.

The pattern analysis showed that the dots pattern is predominant in all the examined groups. Cinotti et al., have also observed that the dots pattern dominated in the studied conjunctival infiltrations. Additionally, they presented a

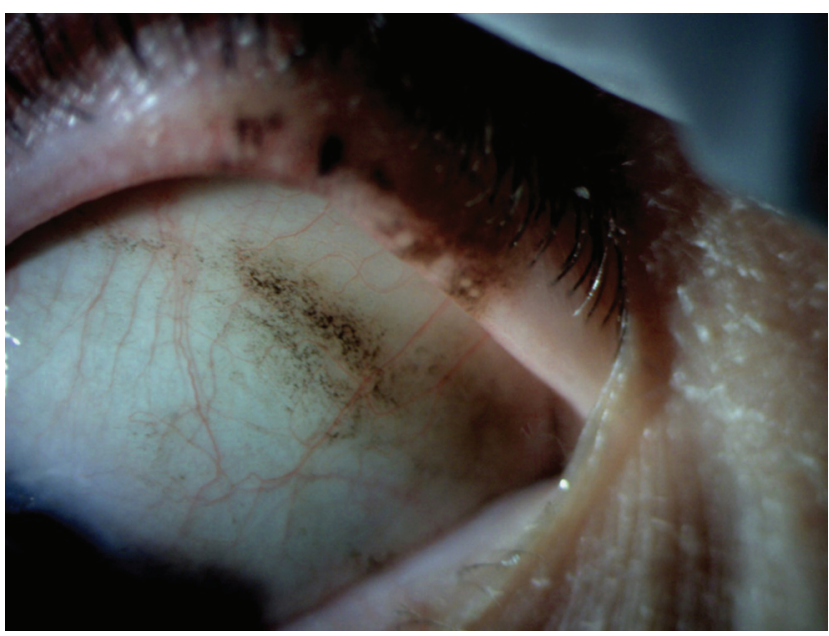

Figure 2. Primary acquired melanosis with atypia - visible black dots within the lesion.

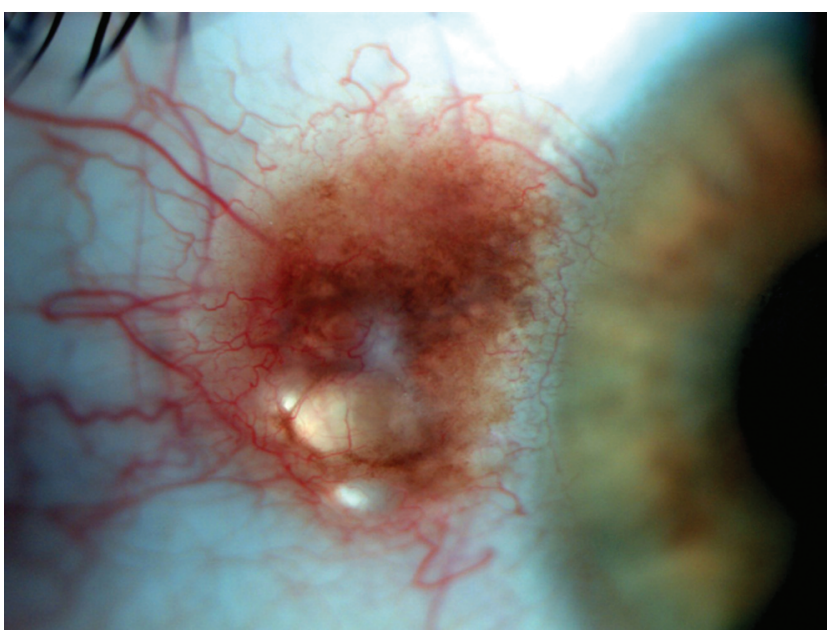

Figure 3. Pigmented conjunctival naevus with cysts.

theory that dots are proliferations of isolated melanocytes and that together with the increase in their number, they blend into an amorphous pattern (21). The amorphous pattern in our study was significantly more frequently a characteristic of melanoma than of pigmented naevi and PAM. A similar correlation concerning various mucous membranes has been described by Cinotti et al. and Lin et al. $(21,27,28)$. And Blum et al. in turn, have shown that the presence of an infiltration containing an amorphous area with blue, grey or white colour on the mucous membrane has $100 \%$ sensitivity for melanoma (23). This fact is confirmed by the published case reports, where the presence of a structureless pattern in conjunctival melanoma was also observed $(29,30)$. 
Table IV. The results of dermatoscopy for the groups with PAM with atypia and PAM without atypia.

\begin{tabular}{|c|c|c|c|}
\hline & $\begin{array}{l}\text { PAM without } \\
\text { atypia }(n=40)\end{array}$ & $\begin{array}{l}\text { PAM with } \\
\text { atypia }(\mathrm{n}=40)\end{array}$ & $p$-Value \\
\hline Elevated lesion & $3(7.5)$ & $1(2.5)$ & 0.615 \\
\hline \multicolumn{3}{|l|}{ Pattern } & - \\
\hline Number of patterns & & & 0.204 \\
\hline 1 & $13(32.5)$ & $8(20.0)$ & \\
\hline$\geq 2$ & $27(67.5)$ & $32(80.0)$ & \\
\hline Pattern asymmetry (chaos) & $0(0.0)$ & $10(25.0)$ & 0.001 \\
\hline Lines & $25(62.5)$ & $18(45.0)$ & 0.116 \\
\hline Dots & $37(92.5)$ & $37(92.5)$ & 1.000 \\
\hline Globules & $0(0.0)$ & $2(5.0)$ & 0.494 \\
\hline Circles & $0(0.0)$ & $0(0.0)$ & - \\
\hline Pseudopods & $0(0.0)$ & $0(0.0)$ & - \\
\hline Structureless & $5(12.5)$ & $22(55.0)$ & $<0.001$ \\
\hline \multicolumn{4}{|l|}{ Colour } \\
\hline $\begin{array}{l}\text { Number of colours, average } \\
\text { Number of colours: }\end{array}$ & \multicolumn{2}{|c|}{ Number of colours: } & 0.001 \\
\hline 1 & $35(87.5)$ & $9(22.5)$ & $<0.001$ \\
\hline 2 & $4(10.0)$ & $19(47.5)$ & \\
\hline 3 & $1(2.5)$ & $11(27.5)$ & \\
\hline 4 & $0(0.0)$ & $1(2.5)$ & \\
\hline 5 & $0(0.0)$ & $0(0.0)$ & \\
\hline 6 & $0(0.0)$ & $0(0.0)$ & \\
\hline Colour asymmetry (chaos) & $0(0.0)$ & $10(25.0)$ & 0.001 \\
\hline Light brown & $30(75.0)$ & $21(52.5)$ & 0.036 \\
\hline Dark brown & $15(37.5)$ & $33(82.5)$ & $<0.001$ \\
\hline Black & $1(2.5)$ & $24(60.0)$ & $<0.001$ \\
\hline White & $0(0.0)$ & $0(0.0)$ & - \\
\hline Gray & $0(0.0)$ & $5(12.5)$ & 0.055 \\
\hline Pink & $0(0.0)$ & $1(2.5)$ & 1.000 \\
\hline \multicolumn{4}{|l|}{ Blood vessels } \\
\hline \multicolumn{4}{|l|}{$\begin{array}{l}\text { Symmetry of the vascular } \\
\text { pattern: }\end{array}$} \\
\hline Polymorphous vessels & $0(0.0)$ & $1(2.5)$ & 0.359 \\
\hline Monomorphous vessels & $0(0.0)$ & $1(2.5)$ & \\
\hline No vessels & $40(100.0)$ & $38(95.0)$ & \\
\hline \multicolumn{4}{|l|}{ Clues to malignancy } \\
\hline Eccentric structureless zone & $0(0.0)$ & $3(7.5)$ & 0.241 \\
\hline Gray structureless area & $2(5.0)$ & $5(12.5)$ & 0.432 \\
\hline Black dots & $1(2.5)$ & $25(62.5)$ & $<0.001$ \\
\hline Segmental pseudopods & $0(0.0)$ & $0(0.0)$ & - \\
\hline Peripheral feeder vessel & $0(0.0)$ & $0(0.0)$ & - \\
\hline Cysts & $0(0.0)$ & $0(0.0)$ & - \\
\hline
\end{tabular}

Significant $p$-Values are shown in bold.

Blum et al. have also observed that colour has more significance than structure in the dermatoscopic diagnostics of the pigmented lesions of mucous membranes. The presence of a grey, blue or white colour argues in favour of the diagnosis of melanoma, especially when this colour coexists with an amorphous pattern (23). In our studied group, CMM, more frequently than naevi, contained a black or grey colour and, in comparison with PAM with atypia - grey and rose. The presence of a white colour was found solely in the
CMM group. A black colour in turn was observed with similar frequency in the premalignant lesions group (PAM with atypia) and malignant ones (CMM). Cinotti et al. have confirmed the correlation of a grey colour with the diagnosis of conjunctival melanoma in comparison with the naevus, and also the melanoma correlation with a grey, blue or black colour in comparison with PAM (without differentiation into PAM with or without atypia) $(21,27)$. It is interesting that the presence of a grey colour is considered to be related to the presence of melanophages and is indicative of inflammation $(27,28,31)$. Tosi et al., in turn, in the analysis of 39 conjunctival pigmented lesions, have observed that the lesions occurring in CMM were darker and had more internal contrast than benign lesions (15).

In our study group, melanomas, in comparison with naevi and PAM, were characterised by the presence of a higher colour number and had often more than 2 colours. Also, Linn et al. and Cinotti et al. have observed the predominance of multi-colour infiltrations in the group of melanomas of mucous membranes $(21,27,28)$, whilst Ronger-Savle et al. have shown that melanomas usually have three or more colours (32). Hajar-Serviansky et al. have described a case of a 7-colour melanoma of the lip mucous membrane (33). Giorgi et al. in a study of the dermatoscopic picture of small skin melanomas, made the hypothesis that colour variegation comprises the most alternated parameter of dermatoscopic criteria (34). It is known that in the case of skin melanomas, the "three-colour test" is useful, yet independently it is not a sufficient diagnostic criterion $(35,36)$.

Apart from pattern asymmetry, colour asymmetry is the main diagnostic criterion in the method of pattern analysis for skin lesions developed by Kittler (19). The presence of this type of asymmetry was observed much more frequently in the CMM, than in other studied groups. To the best of our knowledge, so far colour asymmetry was not evaluated in reference to the melanocytic infiltration of the conjunctiva. Olszewska et al. have described that irregular pigmentation is characteristic of oral melanoma, whereas Linn et al. and Matsushita et al. have defined an irregular pigment network as typical of mucous membrane melanoma $(28,37,38)$.

In the model of pattern analysis, proposed by Kittler, the lack of pattern symmetry or colour in skin infiltrations excludes the presence of a cancerous lesion thus, excluding the necessity of a tumour biopsy (19). In spite of the observations made by Blum et al., in the case of dermatoscopic diagnosis of pigmented lesions of mucous membranes, the analysis of the pattern is more important than that of the colour; in our study we showed a significantly larger frequency of pattern asymmetry in CMM in comparison with pigmented lesions and with PAM with atypia as well as in PAM with atypia in comparison with PAM without atypia $(19,23)$. Cinotti et al. in the analysis of the dermatoscopic picture of conjunctival infiltrations, 
observed that CMM is characterised by irregularly distributed dots (21). A similar dermatoscopic picture has been described in the presentation of oral cavity melanomas $(33,37)$. Ronger-Savle et al. using the diagnostics algorithm for the diagnosis of melanoma in the case of vulvar lesions, observed that vulvar melanomas are characterised by an irregular pattern (32). It has also been shown that an atypical pigmented network has a high specificity for the diagnosis of small skin melanoma (34).

The presumption in the analysis model in Kittler's pattern is that skin melanomas, apart from pattern asymmetry and colour asymmetry, usually contain one of the clues to malignancy (19). Analysis of the pictures of conjunctival infiltrations in the melanoma group allowed us to observe a significantly higher frequency of polymorphic vessels, peripheral structureless areas and grey structures as well as segmental pseudopods. Other clues to malignancy described by Kittler for skin lesions were not present in our study material (19).

On the basis of the observations of conjunctival lesions, we have additionally established our own clues to malignancy, such as the presence of black dots accumulations of pigment within the entire lesion (not only placed peripherally), grey structureless areas, and peripheral feeder vessels; and significantly, we observed a more frequent occurrence of the above clues in the melanoma group.

The significance of the presence of polymorphic vessels in the skin melanoma as one of the most important diagnostic criteria has been described by JaworekKorjakowska, who used a fully automated machine for their identification (39). Olszewska described polymorphic vessels as one of the diagnostic criteria in the melanomas of the mucous membrane of the oral cavity, whilst Ronger-Savle et al. referred to the presence of such vessels in vulvar melanoma $(32,37)$. Shields et al., in their study of a larger group of conjunctival infiltrations, described the presence of feeder or intrinsic vessels as the criteria differentiating CMM from PAM, apart from the thickness of the lesion (greater than $1 \mathrm{~mm}$ ), lack of pigmentation, the presence of cysts, haemorrhaging, older age and tarsal location (24). Similar results were observed also in our study group, among which vascular polymorphism was significantly more frequent in CMM than in naevus and PAM with atypia.

An interesting observation, which according to the best of our knowledge has not been described yet, is the presence of a clue to malignancy in the form of black dots throughout the entire volume of the conjunctival lesion. In the analysed cases, this clue was significantly more frequent in the premalignant and malignant lesions (CMM and PAM with atypia) than in benign lesions (naevi and PAM without atypia).

In our analysis, cysts were present only in the naevi (35\%), which suggests that their presence is typical for naevi. The results of other researchers who used a more detailed imaging method, such as optical coherent tomography (OCT) of the anterior eye segment, also confirm these observations (1-3, 8). Cinotti et al. observed the presence of cysts in $40 \%$ of conjunctival pigmented lesions, whilst in the case of melanoma - there were no cysts at all (21); interestingly in a larger study by Shields et al., cysts were found only in $7 \%$ of CMM cases, with the authors observing a connection between the presence of cysts and the development of melanoma on the foundation of naevi (24). Alzahrani et al. have studied PAM (both with atypia and without atypia) with the use of OCT, and found no cysts in any of the studied cases (2).

It is believed that clinical differentiation between PAM without atypia and PAM with atypia is very difficult, if not impossible, and only a histopathological assessment allows for making the final diagnosis (4). In our study group, both types of PAM were usually flat lesions, not vascularised, with a dominating pattern of dots and lines. Moreover, Cinotti et al., when describing the picture of PAM in a dermatoscopic examination, observed that the lesions exhibited a brown pigmentation (mainly light, less frequently - dark) distributed in dots that could be confluent in a structureless pattern. However, they did not observe any differences between PAM with atypia and without atypia in the clinical examination (21). Mannone et al., in their description of dermatoscopic features of mucosal melanosis (genital and oral), observed two dominating patterns: structureless or parallel. They also observed that melanosis may be an elevated lesion - a feature which we have also observed in isolated cases (31). Olszewska et al., in the examination of the dermatoscopic image of oral melanosis, observed the presence of brown to black, flat, regular, homogeneous lesions with a diffuse pigmentation, differing from melanoma by their lack of brown globules, radial streaming and pseudopods (37). Cinotti et al., in their study of 55 cases of mucous membrane melanoses, observed that the majority of them consisted of two patterns and none of them had more than 2 colours (27).

In the observations made by Shields et al., the only multivariable factor predictive of a progression from PAM to CMM was the development of PAM in a clockwise manner (7). The clinical criteria for PAM, according to Shields et al., comprise one or more patches of acquired asymmetric, flat, non-cystic conjunctival brown pigmentation of at least $1 \mathrm{~mm}$ in diameter $(6,7)$. To the best of our knowledge, our work has been the first to describe the differences in the clinical examination between PAM with atypia and PAM without atypia on the basis of dermatoscopic criteria. In the case of atypia, we observed a more frequent asymmetry of pattern and colour, higher number of colours, the presence of amorphous patterns, a black colour and black dots. PAM without atypia had, in turn, more frequently a single colour and this frequency was statistically significant. 


\section{Conclusion}

This is the first extensive report which analyses 4 groups of histologically different melanocytic lesions of the conjunctiva with regards to the presence and frequency of the occurrence of all features evaluated in dermatoscopy. It turns out that the majority of typical features taken into consideration in dermatoscopy are also present in pigmented lesions of the conjunctiva and may be useful for their differential diagnosis. Thanks to this, the algorithm described by Kittler for the analysis of the pattern of skin lesions, also allows for a credible differentiation between CMM and pigmented naevus and PAM. Additionally, it was observed that the clues to malignancy typical for conjunctival lesions, such as the presence of black dots within their entire volume (not only peripherally), grey structureless areas and peripheral feeder vessels, occur more frequently in the CMM group. It also turns out that on the basis of the analysis, some credible criteria can be distinguished and this allows for differentiation between PAM with atypia and PAM without atypia in the slit lamp. Whilst, so far, these two conditions could be differentiated solely on the basis of the extensiveness of the infiltration or time span of its increase. There is a need to intensify research, which would result in the development of an algorithm of the examination with clear-cut criteria for small pigmented conjunctival lesions (like in the case of dermatoscopy), thereby facilitating the diagnosis of small tumours.

Comprehensive and large-scale studies should follow this preliminary report to evaluate the prognostic status of the characteristics evaluated in dermatoscopy for conjunctival melanocytic tumours such as naevus, PAM with and without atypia and melanoma.

\section{Conflicts of Interest}

The Authors declare no conflicts of interest in relation to this study.

\section{Authors' Contributions}

M.D-K.: Conceptualization, methodology, investigation, data curation, writing - original draft, visualization, formal analysis; B.RD.: conceptualization, methodology, investigation, data curation, writing - review \& editing; J.K.: methodology, writing - review \& editing, investigation, visualization; I.K-B.: methodology, writing review \& editing, investigation; A.M.: conceptualization, methodology, investigation, supervision; writing - review \& editing; project administration, formal analysis, data curation. All Authors have reviewed the article and approved the submitted version.

\section{References}

1 Shields CL, Belinsky I, Romanelli-Gobbi M, Guzman JM, Mazzuca D Jr, Green WR, Bianciotto C and Shields JA: Anterior segment optical coherence tomography of conjunctival nevus.
Ophthalmology 118(5): 915-919, 2011. PMID: 21146221. DOI: 10.1016/j.ophtha.2010.09.016

2 Alzahrani YA, Kumar S, Abdul Aziz H, Plesec T and Singh AD: Primary acquired melanosis: clinical, histopathologic and optical coherence tomographic correlation. Ocul Oncol Pathol 2(3): 123-127, 2016. PMID: 27390743. DOI 10.1159/000440960

3 Levecq L, De Potter P and Jamart J: Conjunctival nevi clinical features and therapeutic outcomes. Ophthalmology 117(1): 3540, 2010. PMID: 19896191. DOI: 10.1016/j.ophtha.2009.06.018

4 Oellers P and Karp CL: Management of pigmented conjunctival lesions. Ocul Surf 10(4): 251-263, 2012. PMID: 23084146. DOI: 10.1016/j.jtos.2012.08.002

5 Shields CL and Shields JA: Tumors of the conjunctiva and cornea. Indian J Ophthalmol 67(12): 1930-1948, 2019. PMID: 31755426. DOI: 10.4103/ijo.IJO_2040_19

6 Shields JA, Shields CL, Mashayekhi A, Marr BP, Benavides R, Thangappan A, Phan L and Eagle RC Jr: Primary acquired melanosis of the conjunctiva: risks for progression to melanoma in 311 eyes. The 2006 Lorenz E. Zimmerman lecture. Ophthalmology 115(3): 511-519.e2, 2008. PMID: 17884168. DOI: $10.1016 /$ j.ophtha.2007.07.003

7 Shields JA, Shields CL, Mashayekhi A, Marr BP, Benavides R, Thangappan A, Phan L and Eagle RC Jr: Primary acquired melanosis of the conjunctiva: experience with 311 eyes. Trans Am Ophthalmol Soc 05: 61-71, discussion 71-2, 2007. PMID: 18427595.

8 Brownstein S: Malignant melanoma of the conjunctiva. Cancer Control 11(5): 310-316, 2004. PMID: 15377990. DOI: $10.1177 / 107327480401100505$.

9 Novais GA, Fernandes BF, Belfort RN, Castiglione E, Cheema DP and Burnier MN Jr.: Incidence of melanocytic lesions of the conjunctiva in a review of 10675 ophthalmic specimens. Int J Surg Pathol 18(1): 60-63, 2010. PMID: 18611943. DOI: $10.1177 / 1066896908319775$

10 Dębicka-Kumela M, Markiewicz A, Karska-Basta I, Kowal J and Romanowska-Dixon B: Clinical features and histopathological classification of 305 conjunctival tumors surgically treated in a single institution dtudy with particular regard of pigmentation and interview data. Klin Oczna 121(4): 203-208, 2019.

11 Volpini BMF, Maia M, Agi J, Vital J Filho and Lellis RF: Synchronous conjunctival melanoma and lentigo maligna melanoma. An Bras Dermatol 92(4): 565-567, 2017. PMID: 28954115. DOI: 10.1590/abd1806-4841.20176015

12 Shields CL, Markowitz JS, Belinsky I, Schwartzstein H, George NS, Lally SE, Mashayekhi A and Shields JA: Conjunctival melanoma: outcomes based on tumor origin in 382 consecutive cases. Ophthalmology 118(2): 389-395.e1-2, 2011. PMID: 20723990. DOI: 10.1016/j.ophtha.2010.06.021

13 Cohen VM, Ahmadi-lari S and Hungerford JL: Gastric metastases from conjunctival melanoma. Melanoma Res 17(4): 255-256, 2007. PMID: 17625457. DOI: 10.1097/CMR.0b013e3281c4a056

14 Dębicka-Kumela M, Karska-Basta, Markiewicz A, I, Bogdali A, Kowal J and Romanowska-Dixon B: Clinical and histological evaluation of 312 excised conjunctival tumors. Klin Oczna 121(1): 41-46, 2019.

15 Tosi GM, Rubegni P, Schuerfeld K, Toti P, Cevenini G, Dell'Eva G, Andreassi L, Caporossi A and Burroni M: Digital surface microscopy analysis of conjunctival pigmented lesions: a preliminary study. Melanoma Res 14(5): 375-380, 2004. PMID: 15457093. DOI: 10.1097/00008390-200410000-00007 
16 Albreiki DH, Gilberg SM and Farmer JP: Conjunctival malignant melanoma: A rare variant and review of important diagnostic and therapeutic considerations. Saudi J Ophthalmol 26(2): 151-156, 2012. PMID: 23960986. DOI: 10.1016/j.sjopt. 2012.02.006

17 Shields CL: Conjunctival melanoma. Br J Ophthalmol 86(2): 127, 2002. PMID: 11815331. DOI: 10.1136/bjo.86.2.127

18 Furdova A, Pesko K, Strmen P and Kobzova M: Conjunctival nevus and melanoma. Bratisl Lek Listy 108(7): 287-291, 2007. PMID: 17972544.

19 Kittler H, Rosendahl C, Cameron A and Tschandl P: Deramatoscopy: An algorithmic method based on pattern analysis. Gdańsk, Via Medica, pp. 40-165, 206, 2012.

20 Rosendahl C, Tschandl P, Cameron A and Kittler H: Diagnostic accuracy of dermatoscopy for melanocytic and nonmelanocytic pigmented lesions. J Am Acad Dermatol 64(6): 1068-1073, 2011. PMID: 21440329. DOI: 10.1016/j.jaad.2010.03.039

21 Cinotti E, La Rocca A, Labeille B, Grivet D, Tognetti L, Lambert V, Kaspi M, Nami N, Fimiani M, Perrot JL and Rubegni P: Dermoscopy for the diagnosis of conjunctival lesions. Dermatol Clin 36(4): 439-449, 2018. PMID: 30201153. DOI: $10.1016 /$ j.det.2018.05.011

22 Shields CL, Demirci H, Karatza E and Shields JA: Clinical survey of 1643 melanocytic and nonmelanocytic conjunctival tumors. Ophthalmology 111(9): 1747-1754, 2004. PMID: 15350332. DOI: $10.1016 /$ j.ophtha.2004.02.013

23 Blum A, Simionescu O, Argenziano G, Braun R, Cabo H, Eichhorn A, Kirchesch H, Malvehy J, Marghoob AA, Puig S, Ozdemir F, Stolz W, Tromme I, Weigert U, Wolf IH, Zalaudek I and Kittler H: Dermoscopy of pigmented lesions of the mucosa and the mucocutaneous junction: results of a multicenter study by the International Dermoscopy Society (IDS). Arch Dermatol 147(10): 1181-1187, 2011. PMID: 21680757. DOI: 10.1001/ archdermatol.2011.155

24 Shields CL, Alset AE, Boal NS, Casey MG, Knapp AN, Sugarman JA, Schoen MA, Gordon PS, Douglass AM, Sioufi K, Say EA and Shields JA: Conjunctival tumors in 5002 cases. comparative analysis of benign versus malignant counterparts. The 2016 James D. Allen Lecture. Am J Ophthalmol 173: 106133, 2017. PMID: 27725148. DOI: 10.1016/j.ajo.2016.09.034

25 Spiliopoulos K, Peschos D, Batistatou A, Ntountas I, PapoudouBai A, Zioga A, Agnantis N and Kitsos G: Immunohistochemical study of vasculogenic mimicry and angiogenesis in melanocytic tumors of the eye and the periocular area. Anticancer Res 37(3): 1113-1120, 2017. PMID: 28314272. DOI: 10.21873/anticanres. 11424

26 Jahnke A, Makovitzky J and Briese V: Primary melanoma of the female genital system: a report of 10 cases and review of the literature. Anticancer Res 25(3A): 1567-74, 2005. PMID: 16033062 .

27 Cinotti E, Couzan C, Perrot JL, Habougit C, Labeille B, Cambazard F, Moscarella E, Kyrgidis A, Argenziano G, Pellacani $\mathrm{G}$ and Longo C: In vivo confocal microscopic substrate of grey colour in melanosis. J Eur Acad Dermatol Venereol 29(12): 24582462, 2015. PMID: 26403597. DOI: 10.1111/jdv.13394.

28 Lin J, Koga H, Takata $M$ and Saida T: Dermoscopy of pigmented lesions on mucocutaneous junction and mucous membrane. Br J Dermatol 161(6): 1255-1261, 2009. PMID: 19673880. DOI: 10.1111/j.1365-2133.2009.09251.x
$29 \mathrm{Li} \mathrm{K}$ and Xin L: Palpebral conjunctiva melanoma with dermoscopic and clinicopathological characteristics. J Am Acad Dermatol 71(2): e35-37, 2014. PMID: 25037804. DOI: 10.1016/j.jaad.2013.11.011

30 Cinotti E, Singer A, Labeille B, Grivet D, Rubegni P, Douchet C, Cambazard F, Thuret G, Gain P and Perrot JL: Handheld in vivo reflectance confocal microscopy for the diagnosis of eyelid margin and conjunctival tumors. JAMA Ophthalmol 1: 135(8): 845-851, 2017. PMID:28654937. DOI: 10.1001/jamaophthalmol. 2017.2019

31 Mannone F, De Giorgi V, Cattaneo A, Massi D, De Magnis A and Carli P: Dermoscopic features of mucosal melanosis. Dermatol Surg 30(8): 1118-1123, 2004. PMID: 15274702. DOI: 10.1111/j.1524-4725.2004.30337.x

32 Ronger-Savle S, Julien V, Duru G, Raudrant D, Dalle S and Thomas L: Features of pigmented vulval lesions on dermoscopy. Br J Dermatol 164(1): 54-61, 2011. PMID: 20846309. DOI: 10.1111/j.1365-2133.2010.10043.x

33 Hajar-Serviansky T, Gutierrez-Mendoza D, Galvan IL, Lammoglia-Ordiales L, Mosqueda-Taylor A, Hernandez-Cázares Mde L and Toussaint-Caire S: A case of oral mucosal melanoma. Clinical and dermoscopic correlation. J Dermatol Case Rep 6(1): 1-4, 2012. PMID: 22514581. DOI: 10.3315/jdcr.2012.1085

34 de Giorgi V, Savarese I, Rossari S, Gori A, Grazzini M, Crocetti E, Sara Longo A, Oranges T and Massi D: Features of small melanocytic lesions: does small mean benign? A clinicaldermoscopic study. Melanoma Res 22(3): 252-256, 2012. PMID: 22430838. DOI: 10.1097/CMR.0b013e3283527430

35 Fikrle T and Pizinger K: Dermatoscopic differences between atypical melanocytic naevi and thin malignant melanomas. Melanoma Res 16(1): 45-50, 2006. PMID: 16432455. DOI: 10.1097/01.cmr.0000195700.42766.23

36 Blum A, Clemens J and Argenziano G: Three-colour test in dermoscopy: a re-evaluation. Br J Dermatol 150(5): 1040, 2004. PMID: 15149530. DOI: 10.1111/j.1365-2133.2004.05941.x

37 Olszewska M, Banka A, Gorska R and Warszawik O: Dermoscopy of pigmented oral lesions. J Dermatol Case Rep 2(3): 43-48, 2008. PMID: 21886712. DOI: 10.3315/jdcr. 2008.1015

38 Matsushita S, Kageshita $\mathrm{T}$ and Ishihara $\mathrm{T}$ : Comparison of dermoscopic and histopathological findings in a mucous melanoma of the lip. Br J Dermatol 152(6): 1324-1326, 2005. PMID: 15949001. DOI: 10.1111/j.1365-2133.2005.06463.x

39 Jaworek-Korjakowska J: A deep learning approach to vascular structure segmentation in dermoscopy colour images. Biomed Res Int 1: 1-8, 2018. PMID: 30515404. DOI: 10.1155/2018/ 5049390 